\title{
PENGARUH KEPERCAYAAN MEREK, KESADARAN MEREK DAN KUALITAS PRODUK TERHADAP KEPUTUSAN PEMBELIAN SMARTPHONE XIAOMI DI DIY
}

\author{
${ }^{1}$ Isnan Rizki Khoirudin, ${ }^{2}$ Eko Giyartiningrum \\ ${ }^{1,2}$ Program Studi Manajemen Fakultas Ekonomi \\ Universitas Cokroaminoto Yogyakarta
}

Email: isnangaruda@gmail.com, ekogiyarti@gmail.com

\begin{abstract}
This study aims to determine the effect of brand trust, brand awareness and product quality on purchasing decisions for Xiaomi smartphones for all consumers of Xiaomi smartphone users in Yogyakarta. The population used in this study were all consumers who use Xiaomi smartphones in Yogyakarta, with a sample of 100 respondents. The sampling technique used nonprobability sampling with a purposive sampling approach. The data collection technique used a questionnaire. The data analysis method used is multiple linear regression analysis, classical assumption test, hypothesis testing. The results of this study indicate that brand trust and product quality partially influence purchasing decisions. Brand trust, brand awareness and product quality simultaneously influence purchasing decisions.
\end{abstract}

Keywords: brand trust, brand awareness, product quality, purchasing decisions

\section{PENDAHULUAN}

Sekarang ini hampir seluruh penjuru dunia memiliki ponsel pintar (smartphone). Smartphone adalah telepon genggam yang mempunyai kemampuan tingkat tinggi yang sudah menggunakan operasi sistem berbasis android. Terdapat beberapa aspek yang akan mempengaruhi perilaku konsumen terhadap keputusan pembelian suatu produk dan jasa, tentunya para konsumen sudah melihat berbagai aspek yang akan menjadi penentu mengambil keputusan pembelian. Beberapa contoh aspek tersebut adalah kepercayaan merek, kesadaran merek dan kualitas produk.

Kepercayaan pelanggan terhadap merek yang kuat dianggap bagaikan metode yang sangat berarti dalam membangun serta memelihara ikatan dengan pelanggan dalam jangka panjang. Menurut Madeline dan $\mathrm{O}$. Sihombing (2019), kepercayaan didasarkan pada persepsi konsumen bahwa suatu merek tidak hanya dapat diandalkan tetapi juga bertanggung

E-ISSN: 2777-1156 


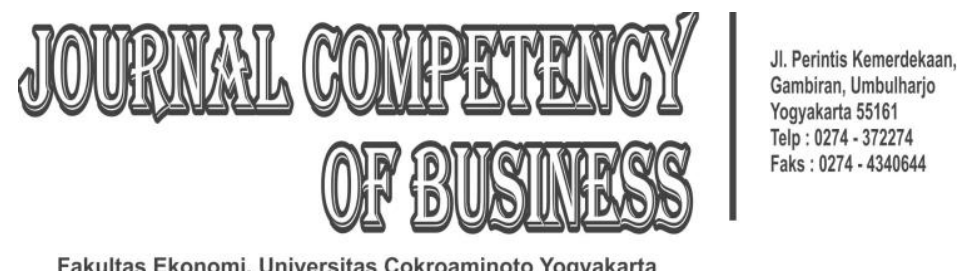

jawab atas kepentingan dan kesejahteraan konsumen, kepercayaan merek juga didetetapkan oleh perasaan percaya diri serta nyaman. Menurut hasil penelitian terdahulu yang dilakukan oleh Trigan dan siregar (2019) kepercayaan merek berpengaruh terhadap keputusan pembelian.

Menurut Timpal dkk (2016), kesadaran merek merupakan tujuan umum komunikasi pemasaran, adanya kesadaran merekyang tinggi diharapkan kapanpun kebutuhan kategori muncul, brand tersebut akan dimunculkan kembali dari ingatan yang selanjutnya dijadikan pertimbangan berbagai alternatif dalam pengambilan keputusan. Membuat kesadaran pelanggan terhadap merek yang kuat adalah kunci bagi perusahaan agar bisa unggul dalam persaingan bisnis, sebab kebanyakan konsumen cenderung memilih produk atau jasa dari merek yang dikenalnya dan inilah yang membuat penjualan semakin meningkat. Dengan demikian perusahaan akan melakukan penyadaran merek terhadap para konsumen, setelah konsumen berhasil mengenali merek merek tersebut maka akan memudahkan perusahaan untuk meningkatkan daya beli produk atau jasa. Menurut hasil penelitian terdahulu yang dilakukan oleh Arivetullatif (2019) kesadaran merek berpengaruh terhadap keputusan pembelian.

Untuk menciptakan sebuah merek yang kuat dibutuhkan kualitas produk yang baik sehingga kualitas merek tersebut akan membuat kepercayaan dan kesadaran terhadap akan konsumen yang sedang melakukan pencarian produk yang coco dibeli. Kualitas produk merupakan mutu dari produk yang diproduksidan kemampuan pelayanan melebihi harapan konsumen, dimana kualitas produk yang baik akan meningkatkan minat beli konsumen. MenurutBudianti dan Anjarwati (2017), kualitas produk sebagai unsur atribut produk yang tidak berwujud, akan tetapi menjadi pertimbangan konsumen dalam membuat suatu keputusan pembelian. Artinya Kualitas suatu produk menjadi salah satu hal terpenting yang menjadi kunci persaingan para pengusaha, para konsumen selalu menginginkan produk bermutu sesuai dengan uang yang telah mereka keluarkan untuk mendapatkan produk tersebut.

\section{KAJIAN PUSTAKA}

\section{Kepercayaan Merek}

Kepercayaan Merek menurut Firmansyah (2019:141) adalah merefleksikan dua komponen penting, yang pertama yakni, keyakinan konsumen bahwa produk tersebut mampu memenuhi nilai yang dijanjikan atau dengan kata lain persepsi bahwa merek tersebut mampu memenuhi harapan konsumen dengan terpenuhinya janji merek yang pada akhirnya menciptakan customer satisfaction, yang kedua, keyakinan konsumen bahwa merek tersebut mampu mengutamakan kepentingan konsumen ketika masalah dalam konsumsi produk muncul secara tidak terduga. Menurut Lau dan Lee dalam Firmansyah (2019:143) ada 3 faktor 
Fakultas Ekonomi, Universitas Cokroaminoto Yogyakarta

kepercayaan merek yaitu: Brand Characteristics, Company Characteristics dan Consumer - Brand Characteristic.

\section{Kesadaran Merek}

Menurut Firmansyah (2019:86) kesadaran merek merupakan tujuan umum komunikasi pemasaran, adanya brand awareness yang tinggi diharapkan kapanpun kebutuhan kategori muncul, brand tersebut akan dimunculkan kembali dari ingatan yang selanjutnya dijadikan pertimbangan berbagai alternatif dalam pengambilan keputusan. Menurut Firmansyah (2019:39) ada 4 faktor kesadaran merek yaitu: Diiklankan secara luas, eksistensi, jangkauan distribusi yang luas dan merek dikelola dengan baik.

\section{Kualitas Produk}

Menurut Budianti dan Anjarwati (2017) kualitas produk sebagai unsur dari atribut produk merupakan salah satu atribut yang dianggap penting bagi konsumen, kualitas produk akan memberikan pengaruh yang besar terhadap keputusan pembelian.

\section{Keputusan Pembelian}

Menurut Tarigan dan Siregar (2019),pengambilan keputusan secara umum diartikan sebagai penilaian terhadap sebuah produk baik barang maupun jasa dan menjatuhkan pilihan terhadap produk tersebut. Secara sederhana dapat diartikan sebagai suatu tindakan atau perilaku konsumen jadi atau tidaknya melakukan suatu pembelian atau transaksi. Menurut Firmansyah (2019:205), ada beberapa tahapan dalam mengambil keputusan yaitu: pengenalan masalahpencarian informasi, evaluasi alternatif, keputusan pembelian dan perilaku pasca pembelian.

\section{Hipotesis Penelitian}

$\mathrm{H}_{1}$ : Hubungan antara kepercayaan merek terhadap keputusan pembelian.

$\mathrm{H}_{2}$ : Hubungan antara kesadaran merek terhadap keputusan pembelian.

$\mathrm{H}_{3}$ : Hubungan antara kualitas produk terhadap keputusan pembelian.

\section{METODE PENELITIAN}

\section{Jenis Penelitian}

Jenis penelitian ini menggunakan pendekatan kuantitatif dengan metode penelitian survei. 


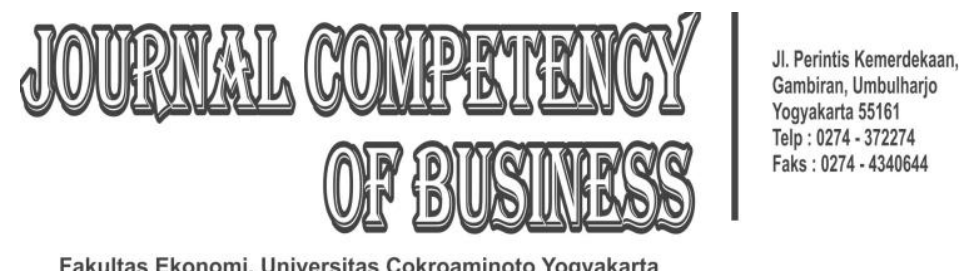

Fakultas Ekonomi, Universitas Cokroaminoto Yogyakarta

\section{Populasi dan sampel}

Populasi yang digunakan dalam penelitian ini adalah seluruh konsumen yang menggunakan produk smartphone merekXiaomi di provinsi Yogyakarta.

Teknik pengambilan sampel dalam penelitian ini menggunakan nonprobability sampling dengan pendekatan purposive sampling, kriteria atau pertimbangan yang telah ditentukan oleh peneliti adalah konsumen yang sudah pernah membeli dan menggunakan smartphone Xiaomi di Yogyakarta. Untuk menentukan jumlah sampel yang digunakan peneliti menggunakan rumus Sugiyono (2019:136), berdasarkan perhitungan rumus tersebut maka sampel yang digunakan sebesar 100 responden.

\section{Sumber Data}

Data primer yang digunakan dalam penelitian ini merupakan data yang diperoleh dari jawaban responden melalui kuesioner tentang pengaruh kepercayaan merek, kesadaran merek dan kualitas produk terhadap keputusan pembelian.

Data sekunder yang digunakan dalam penelitian ini diperoleh dari jurnaljurnal dan buku-buku. sumber tersebut juga digunakan untuk mendapatkan pengetahuan yang lebih mendalam mengenai pengertian serta konsepkonsep mengenai variabel penelitian yang digunakan dalam penelitian ini.

\section{Metode Pengumpulan Data}

Metode pengumpulan data dalam penelitian ini menggunakan metode kuesioner atau angket. Kuesioner tersebut berisi tentang pernyataan mengenai identitas responden dan digunakan untuk mendapatkan data tentang kepercayaan merek, kesadaran merek, kualitas produk dan keputusan pembelian.

\section{HASIL PENELITIAN}

Berdasarkan pada tabel 1 menunjukkan bahwa variabel kesadaran merek tidak berpengaruh secara parsial terhadap keputusan pembelian, sedangkan untuk uji $\mathrm{F}$ berpengaruh secara simultan terhadap keputusan pembelian. 
Fakultas Ekonomi, Universitas Cokroaminoto Yogyakarta

Tabel 1. Hasil Regresi

\begin{tabular}{|c|c|c|c|c|c|}
\hline \multirow{2}{*}{ Model } & \multicolumn{2}{|c|}{$\begin{array}{l}\text { Unstandardized } \\
\text { Coefficients }\end{array}$} & \multirow{2}{*}{$\begin{array}{c}\text { Standardized } \\
\text { Coefficients } \\
\text { Beta } \\
\end{array}$} & \multirow{2}{*}{$\mathrm{t}$} & \multirow{2}{*}{ Sig. } \\
\hline & $\mathrm{B}$ & Std. Error & & & \\
\hline (Constant) & .925 & 2.096 & & .441 & .660 \\
\hline $\begin{array}{l}\text { Kepercayaan } \\
\text { Merek }\end{array}$ & .615 & .154 & .367 & 3.982 & .000 \\
\hline Kesadaran Merek & .156 & .108 & .149 & 1.443 & .152 \\
\hline Kualitas Produk & .574 & .134 & .423 & 4.295 & .000 \\
\hline
\end{tabular}

F (SIMULTAN)

120.193

\section{Adjusted R Square}

.783

Sumber: Data Primer diolah, 2021

\section{PEMBAHASAN}

\section{Pengaruh Kepercayaan Merek Terhadap Keputusan Pembelian}

Dengan melihat hasil penelitian yang dilakukan, diperoleh hasil pengujian hipotesis 1 yaitu hubungan antara kepercayaan merek terhadap keputusan pembelian, kepercayaan merek memiliki pengaruh secara parsial terhadap keputusan pembelian. Hasil ini menunjukkan keputusan pembelian dipengaruhi oleh kepercayaan merek. Hasil penelitian ini sejalan dengan penelitian yang dilakukan Agustyan dan Baehaqi (2020), yang menyatakan bahwa kepercayaan merek berpengaruh terhadap keputusan pembelian smartphone Xiaomi. Dengan demikian semakin tinggi pengaruh kepercayaan merek maka semakin tinggi pula pengaruh terhadap keputusan pembelian smartphone Xiaomi.

Xiaomi merupakan smartphone yang banyak digemari oleh masyarakat karena memiliki reputasi yang baik. perusahaan Xiaomi dari tahun ke tahun selalu memberikan fitur-fitur dan selalu berinovasi dengan harga 


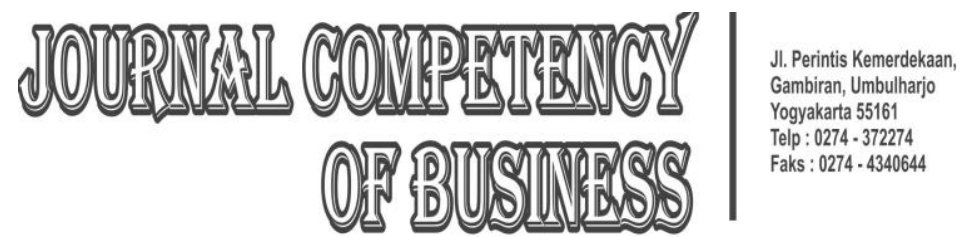

Fakultas Ekonomi, Universitas Cokroaminoto Yogyakarta

yang terjangkau sehingga produk Xiaomi dipercaya oleh banyak kalangan pada saat ini juga. Strategi pemasaran yang baik, selalu membuat desain produk yang elegan, harga yang terbilang murah serta performa yang tak kalah dengan kompetitor lainnya, adanya dukungan komunitas yang baik membuat Xiaomi merupakansmartphone yang terbilang banyak peminatnya.

\section{Pengaruh Kesadaran Merek Terhadap Keputusan Pembelian}

Dengan melihat hasil penelitian yang dilakukan, diperoleh hasil pengujian hipotesis 2 yaitu hubungan antara kesadaran merek terhadap keputusan pembelian, kesadaran merek tidak memiliki pengaruh secara parsial terhadap keputusan pembelian. Hasil ini menunjukkan keputusan pembelian tidak dipengaruhi oleh kesadaran merek. Menurut pendapat si peneliti kesadaran merek sebenarnya berpengaruh namun tidak signifikan terhadap keputusan pembelian. Hal ini dikarenakan konsumen lebih cenderung memilih merek yang sudah dipercayainya dan kualitas yang baik dengan harga yang murah. Hasil ini di perjelas oleh penelitian terdahulu yang dilakukan oleh Porajow, Kalangi dan Tamengkal (2020), menyatakan kesadaran merek berpengaruh secara parsial terhadap keputusan pembelian smartphone Xiaomi, namun kesadaran merek masih belum terlalu kuat dalam mempengaruhi keputusan pembelian, masih banyak faktor lain seperti kualitas dan harga produk.

Kesadaran merek merupakan tingkat pengakuan konsumen terhadap merek tersebut, kesadaran merek memiliki beberapa tingkatan yang paling tinggi adalah top of mind. Top of mind merupakan kesanggupan merek berada pada benak konsumen atau pengakuan konsumen terhadap merek bahwa merek tersebut adalah salah satunya dari berbagai merek lainnya. Hal ini sulit untuk diwujudkan oleh perusahaan smartphone Xiaomi, mengingat banyaknya persaingan yang ketat membuat merek Xiaomi sulit menjadi yang pertama dalam benak konsumen.

\section{Pengaruh Kualitas Produk Terhadap Keputusan Pembelian}

Dengan melihat hasil penelitian yang dilakukan, diperoleh hasil pengujian hipotesis 3 yaitu hubungan antara kualitas produk terhadap keputusan pembelian, kualitas produk memiliki pengaruh secara parsial terhadap keputusan pembelian. Hasil ini menunjukkan keputusan pembelian dipengaruhi oleh kualitas produk. Hasil penelitian ini sejalan dengan penelitian yang dilakukan Amilia dan Asmara (2017), menyatakan kualitas produk berpengaruh signifikan terhadap keputusan pembelian. Pendapat ini diperjelas oleh Budianti dan Anjarwati (2017), semakin tinggi 


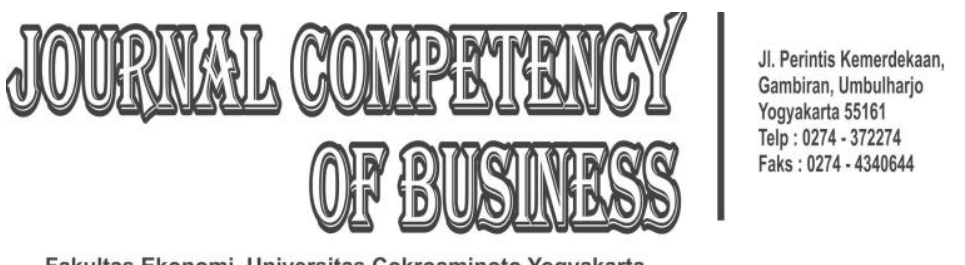

rogyakarta

kualitas produk yang dirasakan oleh konsumen semakin tinggi pula tingkat keputusan pembelian produk tersebut.

Xiaomi merupakan perusahaan smartphone asal china yang memiliki logo dua kata $\mathrm{m}$ dan $\mathrm{i}$ yang memiliki arti mobile internet dan juga memiliki arti mission impossible. Perusahaan Xiaomi memang terkenal dengan harga yang murah tapi perusahaan Xiaomi ingin mewujudkan impiannya tidak bisa mengandalkan harga yang murah saja tetapi juga harus berkualitas.Mengutip dari data IDC, di antara 3 merek teratas Samsung, Huawei dan Xiaomi menjadi top smartphone di seluruh pasar global, artinya perusahaan Xiaomi merupakan perusahaan smartphone pasar ke-3 di dunia, mengirimkan total 46,5 juta unit untuk meraih posisi ke 3 dalam sekala global pada 3 kuartal 2020, hal ini disebabkan oleh permintaan yang kuat di India, China dan Indonesia serta menjadi merek terbesar ketiga di Eropa Barat untuk pertama kalinya. Hal ini juga tidak terlepas dari produk Xiaomi yang hadir dengan harga murah namun tetap memiliki kualitas yang baik.

\section{Uji Simultan (Uji F)}

Dengan melihat hasil penelitian yang dilakukan, diperoleh hasil pengujian hipotesis 4 yaitu hubungan antara kepercayaan merek, kesadaran merek dan kualitas produk terhadap keputusan pembelian smartphone Xiaomi. Sehingga kepercayaan merek, kesadaran merek dan kualitas produk bisa berpengaruh bersamaan terhadap keputusan pembelian.

Semakin tinggi kualitas produk akan semakin tinggi tingkat keputusan pembelian. Tentu saja hal ini akan meningkatkan kepercayaan konsumen dan kesadaran konsumen terhadap merek yang tinggi juga. Penelitian ini juga didukung oleh Helsar, Tobing dan Setiawan (2020) yang menyatakan kualitas produk memiliki kemampuan yang dapat memberikan kepuasan terhadap keputusan. Dengan adanya kepuasan konsumen akan memberikan rasa percaya dan kesadaran konsumen terhadap merek tersebut.

\section{Koefisien Determinasi $\left(\mathbf{R}^{2}\right)$}

Dengan melihat Adjusted $R$ Square sebesar 0,783. Sehingga dapat disimpulkan besarnya pengaruh kepercayaan merek, kesadaran merek dan kualitas produk terhadap keputusan pembelian smartphone Xiaomi sebesar 
Fakultas Ekonomi, Universitas Cokroaminoto Yogyakarta

78,3\% sedangkan 21,7\% dipengaruhi oleh faktor lain yang tidak dimasukkan ke dalam variabel penelitian ini.

Keputusan pembelian memiliki beberapa faktor seperti harga produk, mengingat smartphone Xiaomi adalah produk yang terbilang murah. Hal ini diperjelas oleh peneliti (Budianti and Anjarwati, 2017) menyatakan bahwa harga menjadi faktor penting dalam melakukan keputusan pembelian. Jadi selain kepercayaan merek, kesadaran merek dan kualitas produk masih ada faktor lain untuk menentukan keputusan pembelian smartphone Xiaomi seperti harga produk.

\section{KESIMPULAN DAN SARAN}

Berdasarkan hasil penelitian yang dilakukan, dapat disimpulkan bahwa kepercayaan merek dan kualitas produk berpengaruh terhadap keputusan pembelian. Sedangkan kesadaran merek tidak berpengaruh terhadap keputusan pembelian.

Penelitian ini menggunakan tiga variabel yang mempengaruhi keputusan pembelian yakni kepercayaan merek, kesadaran merek dan kualitas produk. Sehingga masih banyak faktor lain yang mempengaruhi perilaku konsumen dalam melakukan keputusan pembelian smartphone Xiaomi. Sedangkan sampel dalam penelitian ini terbatas yaitu 100 responden yang menggunakan smartphone Xiaomi dengan tingkat provinsi, sehingga data yang diperoleh tidak banyak dan tidak bervariasi. Sehingga penelitian ini memberikan saran kepada penelitian selanjutnya untuk menambah beberapa variabel dan jumlah responden untuk memperoleh hasil yang bervariasi.

\section{DAFTAR PUSTAKA}

Agustyan, R. dan Baehaqi, M. (2020) 'Analisis Pengaruh Online Consumer Review, Warranty Product Dan Brand Trust Terhadap Purchase Decision Smartphone Xiaomi Di Kabupaten Kebumen', Jurnal Ilmiah Mahasiswa Manajemen, Bisnis Dan Akuntansi (Jimmba), 2(2), 240-250.

Amilia, S. dan Asmara, O. (2017) 'Pengaruh Citra Merek, Harga, Dan Kualitas Produk Terhadap Keputusan Pembelian Handphone Merek Xiaomi Di Kota Langsa', Jurnal Manajemen Dan Keuangan Unsam, 6(1), 660-669.

Arivetullatif (2019) 'Pengaruh Brand Awareness, Perceived Quality Dan Brand Association Terhadap Keputusan Pembelian Ulang Smartphone Samsung (Studi Kasus Pada Pengguna Smartphone Samsung Di Kota Padang)', Ensiklopedia Social Review, 1(2), 150-155. 


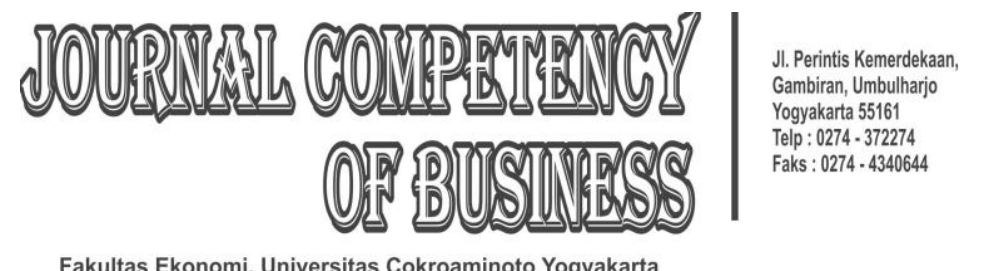

Fakultas Ekonomi, Universitas Cokroaminoto Yogyakarta

Budianti, A. C. dan Anjarwati, A. L. (2017) 'Pengaruh Kualitas Produk Dan Harga Terhadap Keputusan Pembelian Smartphone Xiaomi Redmi 1s (Studi Pada Pengunjung Wtc Surabaya)', Jurnal Ilmu Manajemen (Jim), 5(1), 1-9.

Budianti, A. C. dan Anjarwati, A. L. (2017) 'Pengaruh Kualitas Produk

Dan Harga Terhadap Keputusan Pembelian Smartphone Xiaomi Redmi 1s (Studi Pada Pengunjung Wtc Surabaya)', Jurnal Ilmu Manajemen (Jim), 5(1), 1-9.

Firmansyah, M. A. (2019) Pemasaran: Produk Dan Merek (Planning Dan Strategy). Surabaya: Qiara Media.

Helsar, O., Tobing Dan Setiawan, B. (2020) 'Pengaruh Persepsi Harga, Varian Dan Kualitas Produk Terhadap Keputusan Pembelian Smartphone Xiaomi (Survey Persepsi Mahasiswa Ibik Bogor)', Jurnal Ilmiah Manajemen Kesatuan, 8(2), 95-104.

https://www.idc.com/ (di akses pada tanggal 16-02-2021)

Madeline, S. Dan O. Sihombing, S. (2019) 'The Impacts Of Brand Experiences On Brand Love, Brand Trust, And Brand Loyalty: An Empirical Study', Jurnal Bisnis Dan Manajemen, 20(2), 91-107.

Porajow, K. C., Kalangi, J. A. F.dan Tamengkal, L. F. (2020) 'Pengaruh Kesadaran Merek terhadap Keputusan Pembelian Smartphone Xiaomi di Manado', Jurnal Productivity, 1(5), 446-452.

Sugiyono (2019) Metode Penelitian Kuantitatif, Kualitatif Dan R\&D. Bandung: Alfabeta.

Tarigan, A. dan Siregar, Z. (2019) 'Pengaruh Harga Dan Brand Trust Terhadap Keputusan Pembelian Oppo Smartphone (Studi Kasus Pada Oppo Store, Sinergy Celular Medan)', Jurnal Plans Penelitian Ilmu Manajemen \& Bisnis, 14(1), 17-21.

Timpal, N., Lapian dan Rate, P. Van. (2016) 'Pengaruh Brand Awareness

Dan Brand Attitude Terhadap Keputusan Pembelian Handphone Merek Nokia (Studi Kasus Pada Siswa SMA Dan SMK Di Kota Manado)', Jurnal Berkala Ilmiah Efisiensi, 16(01), 308-317. 